\title{
PELVIC AND PERIPHERAL VENOUS \\ INSUFFICIENCY: DIFFERENT PRESENTATIONS \\ AND COMMON PATHOPHYSIOLOGY
}

\section{Mosaad Soliman*, Mohamed Abo El atta** and Hamed Youssef***}

Mansoura University Hospital, Departments of Vascular surgery*,

Radiology**, and OB/GYN***

\section{ABSTRACT}

Introduction : Varicose veins are related to other diseases including varicocele or utero-ovarian varices. On the base of close physiopathologic relationships between varicose veins and gonadal varicosity we decided to evaluate the features of pelvic venous insufficiency in patients affected by varicose veins.

Methods : Seventy patients with different grades of chronic venous insufficiency (CVI) were included in the study. The patients were evaluated pre-operatively by color Doppler for grading of gonadal varicosity and assessment of valvular incompetence in the peripheral veins. Post-operatively, the number of valves in the stripped veins was correlated to the degree of gonadal varicosity,

Results : Thirty patients were proved to have both peripheral and pelvic venous insufficiency. Higher grades of gonadal varices were associated with lesser number of saphenous valves. There was a significant relation between the Doppler grading of venous reflux in gonadal \& peripheral veins.

Conclusions : The incidence of varicocele associated with CVI was higher than the incidence of isolated varicocele. The bilateral development of gonadal and peripheral varicosity in female patients refers to mechanical compression followed by axial reflux. The association of lesser number of valves in the saphenous veins with higher grades of varicocele raises the possibility of generalized valvular scarcity as a cause of venous insufficiency.

Keywords : Varicose, Varicocele, Doppler.

\section{INTRODUCTION}

Varicocele is an abnormal dilatation of the orthostatic veins of the pampiniform plexus caused by retrograde blood flow. This disease is frequently seen in the adult population and is estimated to account for $30 \%$ of male infertility. In children and adolescents the frequency is 15 to $30 \%$ (1) , increasing with age from $5.7 \%$ at age of 10 to $19.3 \%$ at age of 14 .

The mechanism which causes varicocele has not been completely elucidated. However, it is currently accepted that ostial incontinence of the spermatic vein results in retrograde blood flow.
Other studies have also clarified several anatomic variations in the spermatic vein supply ${ }^{(2)}$. On the other hand, varicose veins present major health problem, causing chronic leg symptoms and disability in a large segment of the population. The prevalence rate in adults shows great geographical variation and increases with age.

Several authors believe that varicoceles and varicose veins of the leg are both due to valvular incompetence (3). The inferior vena cava and common iliac veins are always valveless. The iliac and comon femoral veins do not contain more than one valve, and in $36 \%$ of subjects there is a total absence of valves on one or both sides (4). Competent venous valves aid in efficient 
functioning of the venous pump by preventing blood reflux from the deep to the superficial veins. The possibility of a genetically determined structural defect in the venous wall has also been suggested. Individuals with varicose veins in the lower extremities have been found to have an increased venous distensibility and reduced amounts of collagen and hexosamine in the wall of unaffected veins. In such situations, a sustained elevation in the venous pressure may eventually lead to stretching of the wall and, finally to incompetence of the valves and overdistention of the veins ${ }^{(5)}$.

Connective tissue alteration has been accused to support the development of varicocele ${ }^{(6,7)}$. It has been reported that an inherited weakness of the venous system might be a disposition for varicocele, which is often accompanied by hemorrhoids and varicose veins ${ }^{(8)}$.

The frequency and pathogenesis of varicose veins and varicocele may lead to the assumption that this coincidence may happen more often than previously thought. Moreover there is only limited information available on the treatment strategy in case of combined varicose veins with varicocele. The aim of the present study was to elucidate the true figures of coincidence of gonadal varicosity with chronic venous insufficiency and introduce a surgical plan for simultaneous correction of both disorders.

\section{MATERIALS \& METHODS}

The study group consisted of 70 patients with different grades of chronic venous insufficiency, selected from patients scheduled for saphenectomy and/or subfascial endoscopic perforator surgery ( $S$
E P S) at Mansoura international and Mansoura Insurance Hospitals during the period 2001 to 2005.

The age of these patients ranged from 21 to 43 years (mean, $29 \pm 2.3$ ). Forty eight were males and 22 were females. All patients were examined clinically to determine the grade of chronic venous insufficiency (CVI) and the association of gonadal varicosity. Thirty patients of the screened group (42\%, 22 males \& 8 females) were proved to have both CVI and gonadal varicosity.

Table I summarizes the affected side with gonadal varicosity in patients suffering from CVI. Varicose veins on the left side were associated with bilateral varicocele in $45.4 \%$ (10.22) Whereas the coincidence of left CVI and left varicocele was observed in $27 \%(6 / 22)$ Bilateral varicocele was recorded in equal number of patients with bilateral or right CVI, $3 / 22(13.6 \%)$ on the other hand, isolated right varicocele was not observed in association with any grade of CVI.

In contrary to males, bilateral CVI was associated with bilateral vulval varicosity in $75 \%$ (6/8) while the coincidence of right vulval varicosity and right CVI was observed in $12.5 \%$. The distribution of CVI and their association with different grades of varicocele is shown in Table II Ten patients with grade III CVI were associated with grade 2 or 3 varicocele (Fig. 1) On the other hand, only one patient with grade I CVI was associated with grade 1 varicocele.

Diagnosis was initially made through physical examination of patients with CVI. To avoid interobserver variation, all patients were examined by the same surgeon. A physical examination was performed in a warm room with the patient 
standing by careful scrotal, spermatic cord or vulval evaluation in resting position and during. Valsalva. Vulval varicosity appears as a bunch of dilated veins under the labial skin making a bulge and sagging down of the labia (Fig. 2), and gets transiently engorged with straining or it may extend beyond the skin to involve the vaginal mucosa (Fig 3)( although vulval varicosity can be felt and seen, there is no reports about its grading). However, varicocele has been given a grading system, depending on their severity. A clinical varicocele was typically defined as a visible (grade 3) or palpable distension of the spermatic cord structures on upright examination (grade 2), or palpable distension detected only during a Valsalva manoeuvre (grade 1).

Color Doppler ultrasonography of the scrotum or vulva as well as the affected lower limb with varicose veins was executed on all patients with high frequency duplex echo transducer (7.5 MHZ and higher) equipped with color flow imaging. The transducer was placed on the scrotal or labial surface with the patient in a supine position and abdomen and chest elevated about $15^{\circ}$. In males, the penis was positioned to the anterior abdominal wall and covered with a towel. The transverse diameter of the largest vein in the gonadal plexus was measured during normal respiration and during a Valsalva manoeuvre. The veins were studied by color and pulsed Doppler. Retrograde venous flow in the veins during spontaneous respiration or the Valsalva manoeuvre was noted (Fig 4).

The ultrasound study was considered abnormal if a vein diameter exceeded $3 \mathrm{~mm}$ during any manoeuvre and flow reversal occurred during the Valsalva manoeuvre. The competence of the saphenofemoral junction, the saphenous veins and the presence of incompetent perforators was evaluated. Retrograde venous flow during normal respiration or a Valsalva manoeuvre for longer than 0.5 second was regarded as positive for saphenofemoral incompetence.

\section{surgical technique}

A $4 \mathrm{~cm}$ skin crease incision centered over the femoral artery below the inguinal ligament was made to explore the saphenofemoral junction. The venous tributaries of the long saphenous vein were doubly lighted and divided. Saphenofemoral disconnection was done flush with the femoral vein. A disposable stripper was inserted in the proximal mouth of the saphenous vein and advanced retrogradely beyond the knee join to the Boyd's point (Fig. 5).

The upper skin edge was elevated and blunt dissection was used to expose the external inguinal ring. The spermatic cord was then delivered out of the incision using Babcock forceps. The facial coverings of spermatic cord were split longitudinally and pampiniform plexus of veins were identified, isolated and divided while the stripper was still in position in the saphenous vein (Fig. 6). The process was then repeated with cremasteric plexus with the overall goal was to ligate the abnormal veins while preserving the vas deferens, testicular artery and the lymphatics of the spermatic cord. The testis was delivered off the incision, the tunica was opened, evereted (Fig. 7) and then the testis was replaced in the scrotum and the procedure was ended with stripping of the saphenous vein and attacking incompetent leg perforators if present.

In female patients, the vulval varicosities were traced along the round ligament and divided 
through the groin incision (Fig. 8).

The stripped segment of saphenous vein was split open and the valves were identified and counted. Cross sections of the saphenous vein and the gonadal varicosity were taken, fixed and stained either with hematoxylin and eosin or Masson trichrome to recognize the distribution of fibrous tissue.

\section{RESULTS}

Of the 70 patients with CVI, $32(45.7 \%)$ did not have gonadal varicosity either by physical examination or colored Doppler. Eight patients $(11.4 \%)$ had subclinical gonadal varicosity being presented with impalpable reflux on physical examination but detected by Doppler. The latter group of patients was also excluded from the study.

Of the 30 patients with concomitant CVI and gonadal varicosity, $9(30 \%)$ of the male patients were married and three of them were infertile for an average of 1.5 years. The mean venous diameter of the pampiniform plexus was $3.6 \pm 0.7 \mathrm{~mm}$ and the shape of the veins was tubular in all cases. The mean venous flow velocity was $2.7 \mathrm{~cm} / \mathrm{sec}$ and had an inverse relationship to the diameter of the veins.

Three types of flow patterns were found in the spectral analysis of venous flow:

1- Type I: If the venous flow was directed to the heart and did not change direction with the increase of intra-abdominal pressure.

2- Type II: If the venous flow was directed to the heart, but changing direction with the increase of intra-abdominal pressure.

3- Type III: If the blood flow was directed to the testicles and augmenting with the increase of intra-abdominal pressure. Flow patterns were observed in $13.9,30$, and $56.6 \%$ for type I, II, and III, respectively.

Type I and II were commoner in females whereas type III carried the highest incidence in males. Three patients diagnosed clinically by palpation as type II upgraded to type III by Doppler (Table III).

The degree, extent, and location of reflux in the superficial or deep venous system of the lower limb can be determined with duplex scanning. The velocity of flow is evaluated by means of manual distal compression release or cuff deflation or the patient may be asked to perform Valsalva manoeuvre.

The point of reflux is indicated by an enlarged venous diameter, lack of valve-leaflet coaptation, and bi-directional movement of blood. In 22 patients $(70 \%)$, the saphenofemoral junction was incompetent with a diameter more than $5.8 \mathrm{~mm}$. In 2 patients, the diameter of saphenofemoral junction was $3.5 \mathrm{~mm}$ and in 6 patients it was less than 3.5 mm without overt reflux,. In 19 patients $(63.3 \%)$ incompetent valves of the long saphenous vein were observed especially at the sites of perforating veins.

A mean of $2.4 \pm 0.6$ incompetent perforators were recorded with a diameter more than $3 \mathrm{~mm}$. In the course of surgical exposure, the long saphenous vein was found to be a single continuous trunk in $76.6 \%$ of cases, double in $16.6 \%$, and triple in $6.6 \%$.

In all the patients, the long saphenous vein terminated in the common femoral vein except in a female patient in which the long saphenous vein and its upper tributaries shared a common termination in that vein. In two other females, the 
superficial external pudendal vein was found to be connected to the vulval varicosity.

The number of valves in the stripped segment of saphenous vein was inversely related to the degree of gonadal varicosity. A range of 1 to 3 valves was observed in the veins of patients with grade 3 varicocele (Fig. 9), a range of 4-6 valves was observed in the saphenous veins of patients with grade 2 gonadal varicosity, whereas in grade 1 gonadal varicosity, a range of 5-8 valves was observed in their saphenous veins.

The resected segments of saphenous vein and varicocele were investigated by histological examination using hematoxylin-eosin and Masson trichrome staining. We found no changes in the intima or adventitia and no change in any of the valves of the saphenous vein or varicocele, however, we noticed varying degrees of thinning of the media of the venous wall as well as focal subintimal and medial fibrosis, which coincided with the areas of varicose dilatation between areas that retained their normal configuration (Fig. 10).

\section{DISCUSSION}

Varicose veins are one of the most prevalent chronic conditions in industrialized territories and place a considerable demand on health services. Varicose veins are present in $20-25 \%$ of adult female and $10-15 \%$ of men ${ }^{(9)}$. A large proportion of patients may wish surgery for cosmetic reasons or due to anxiety that their disease may progress to chronic venous insufficiency and ulceration.

Varicose vein surgery is not curative, and early surgery in uncomplicated veins will not prevent development of future varicosities. However, it has been shown, that quality of life is reduced in patients with varicose veins compared with the general population, and that this is improved by surgery ${ }^{(10)}$.

In the past, only large symptomatic varicoceles were treated surgically, but this has been changed, now they should be treated to prevent irreversible damage to the testis. It is therefore, advantageous to identify asymptomatic patients with varicocele who may be at risk of developing infertility afterwards and to detect symptomatizing females with vulval varicosity who do not declare their complaints.

In general, screening for gonadal varicosity is performed with palpation. Although varicocele can be diagnosed as a palpable distension of the spermatic cord, poor accuracy of palpation has been reported (11). Therefore, color Doppler ultrasonography was used as an alternative to palpation in the screening for gonadal varicosity. Ultrasonography combined with color Doppler examination is the method of choice for imaging the gonads ${ }^{(12)}$ and allows more objective and precise assessment of male varicocele ${ }^{(13)}$

Female "varicocele" has been diagnosed by labelled red blood cell angioscintigraphy (14). However, in light of the higher sensitivity and specificity of Doppler examination compared with thermography and angiography, as well as its low cost and noninvasiveness, this became the procedure of choice in the diagnosis of venous reflux in varicocele ${ }^{(15)}$.

In the present study, the upgrading of varicocele from grade 2 to 3 by Doppler compared to palpation in 3 patients confirms the sensitivity of Doppler reported by others ${ }^{(16)}$.

Clinical examination of the lower limb will 
allow assessment of the distribution of varicosities and indicate whether reflux is present in the long or short saphenous system or both. Tests such as the cough, tap and thrill test have been shown to be inaccurate (17). However, the combination of a hand-held Doppler and toumiquet allows reliăble identification of saphenofemoral incompetence (18)

In evaluating the superficial venous system, duplex scanning is invaluable for providing qualitative and quantitative data concerning venous reflux, including the site, degree, and velocity of such reflux ${ }^{(19)}$.

The observation that $70 \%$ of patients in our study group have had incompetence of the saphenofemoral junction which is higher than the incidence (56-60\%) reported by Karadeniz-Biligil et al ${ }^{(20)}$ is due to the difference in the primary disease and the pathology to be screened.

In the present study, the primary disease was CVI of the lower limb and these patients were screened for gonadal varicosities. In the aforementioned study, the authors screened the saphenofemoral junction incompetence in patients with varicocele.

The high incidence of varicose veins and varicocele on the left side has been observed by others $(21,22)$ where varicose veins were found to be $10 \%$ greater on the left side and varicocele was located in the left side in $78-93 \%$ of cases. Reasoning to the foregoing fact has been explained by the pressure exerted by the iliac colon, which crosses directly over the left spermatic vein and left external iliac vein partially obstructing the blood flw, raising the pressure in the corresponding veins distally, and causing them to become varicose.
The bilateral association of CVI and gonadal varicosities in female patients is in favor of the sustained elevation of venous pressure, beyond 300 $\mathrm{mm} \mathrm{Hg}$, caused by pregnancy ${ }^{(23)}$.

Similar to varicose veins, a defect of the valves in the spermatic veins has been proposed as a predisposition for the development of varicocele (24). Valves were found to be present in the testicular veins in only $54 \%$ of males at postmortem examinations (25). Phlebography proved the absence of valves in the testicular vein of varicocele patients ${ }^{(26)}$.

Tibbs and Fletcher ${ }^{(27)}$ have shown that simple varicose veins of the leg always show downward flow, and this reversed flow is likely to be the stimulus to the development of tortuous veins. It occurs when incompetent valves allow a gravitational downfall.

As the patient walks, an endless retrograde circuit down the superficial veins is created. This strong turbulent reverse flow is the mechanical force causing veins to become varicose. It seems highly probable that the varicocele is another example of a venous retrograde circuit and is, therefore, the result of gravitational down flow in an incompetent testicular vein to the pampiniform plexus and out to pelvic veins; it is a dynamic phenomenon and not due to mere static distention and is a cumulative process providing its own stimulus to increasing magnitude ${ }^{(28)}$.

Pertinent to the explanation of the coincidence of gonadal and limb varices, are the possible anastomoses between the subcutaneous and intrascrotal veins ${ }^{(29)}$. Therefore, the blood can reflux from the incompetent saphenous vein through the external pudendal vein to the scrotal veins which communicate with the cremasteric and 
pampiniform plexus. Support for this explanation comes from the finding of termination of the exteranal pudendal vein into the vulval varices during operative tracing of that vein.

It has been clearly demonstrated that stripping reduces the rate of recurrence ${ }^{(30)}$. Studies have shown that incompetence in perforating veins may be reversed following saphenous vein surgery in the presence of a normal deep venous system (31). Although the significance of perforating veins remains unclear even in patients with venous ulceration, however, several surgical attempts have been designed to divide perforating veins and many of them were associated with considerable morbidity.

Subfascial endoscopic perforator surgery (SEPS) has allowed perforating veins to be divided effectively with minimal morbidity. SEPS is not indicated in primary uncomplicated veins but may have a role in addition to saphenous ligation in patients with venous ulcers and who have no evidence of previous deep vein thrombosis ${ }^{(32)}$.

Some argument that may be raised against varicocele repair in the current study is that it is an empiric therapy; that in the majority of successfully treated cases, the pathophysiologic basis for favorable outcome remains obscure $(33,34)$

Opponents point to an additional controversy regarding the cause-effect relationship of varicocele and male infertility. There are patients who remain infertile despite surgical correction of varicocele, and conversely, patients who become fertile without therapeutic intervention, and patients with varicocele who are normally fertile ${ }^{(35)}$. However, just because the mechanism is not clearly established does not mean that there is not an effect. It is known that reflux of venous blood into the pampiniform plexus is involved ${ }^{(36)}$.

Macroscopic and microscopic testicular damage associated with varicocele is also well documented ${ }^{(37)}$. It is also reported that $77 \%$ of patients with a varicocele had either unilateral or bilateral testicular atrophy and by using caliper measurements, it has been demonstrated that both testicles of patients with varicocele were significantly smaller than testes of normal individuals $(38,39)$.

In the light of the debate that still exists on the pros and cons of varicocele treatment, it is justifiable to do varicocelectomy in the course of treatment of CVI to stop its inveitable microscopic testicular damage.

Because of the lack of consensus regarding the diagnostic clinical criteria of female varicocele, they require diagnosis both by clinical and sonographic means and their treatment is considered only in those patients with an obvious complaint of heaviness during the premenstrual time or those who presented with prominent vulval varicosity during pregnancy.

Varicose veins and varicocele are frequent disorders with related complaints. they may appear coincidently more often than previously thought due to similar pathogenesis. Our results not only support the idea that valvar insufficiency plays a major role in the etiology of gonadal varicosity, but also to the high concurrence of gonadal varicosity and valve incompetence of the venous system of the lower limbs. Based on these results, we suggest that the clinical examination and duplex scanning of the gonads in all patients affected by CVI should be carried out so that optimal surgery could be planned and performed for both disorders. 
Table I : The side of gonadal and limb varicosity.

\begin{tabular}{|l|c|c|c|c|c|c|}
\hline \multicolumn{2}{|c|}{ CVI } & \multicolumn{3}{c|}{ Varicocele } & \multicolumn{3}{c|}{ Vulval varicosity } \\
\hline & RT & LT & Bil & RT & LT & Bil \\
\hline Rt & 0 & 0 & 3 & 1 & 0 & 0 \\
\hline Lt & 0 & 6 & 10 & 0 & 1 & 0 \\
\hline Bilateral & 0 & 0 & 3 & 0 & 0 & 6 \\
\hline
\end{tabular}

Rt, right Lt; left $\quad$ Bil; bilateral

Table II : The associated grade of varicocele and CVI by physical examination.

\begin{tabular}{|l|c|c|c|}
\hline \multicolumn{1}{|c|}{ CVI } & \multicolumn{3}{|c|}{ Varicocele } \\
\hline & 1 & 2 & 3 \\
\hline I & 1 & 0 & 0 \\
\hline II & 0 & 3 & 2 \\
\hline III & 0 & 3 & 7 \\
\hline IV & 0 & 1 & 0 \\
\hline V & 0 & 0 & 0 \\
\hline VI & 0 & 2 & 3 \\
\hline
\end{tabular}

Table III : Color Doppler grading of gonadal varicosity.

\begin{tabular}{|l|c|c|c|}
\hline & Males (n. 22) & Females (n. 8) & Total \\
\hline Grade 1 & 1 & 3 & $4(13.4 \%)$ \\
\hline Grade 2 & 6 & 3 & $9(30 \%)$ \\
\hline Grade 3 & 15 & 2 & $17(56.6 \%)$ \\
\hline
\end{tabular}



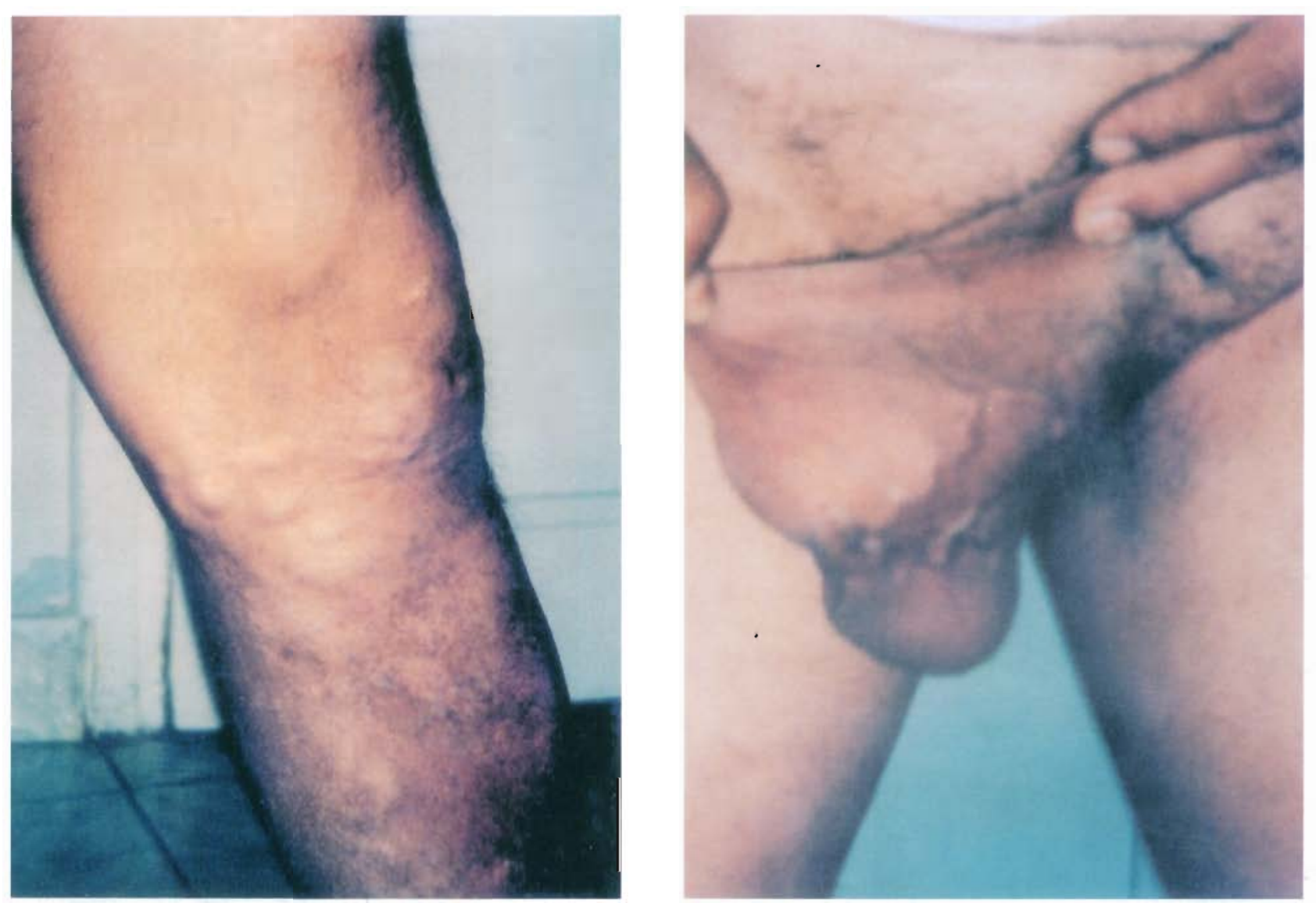

Fig. 1. Grade III CVI associated with grade 3 varicocele (b)

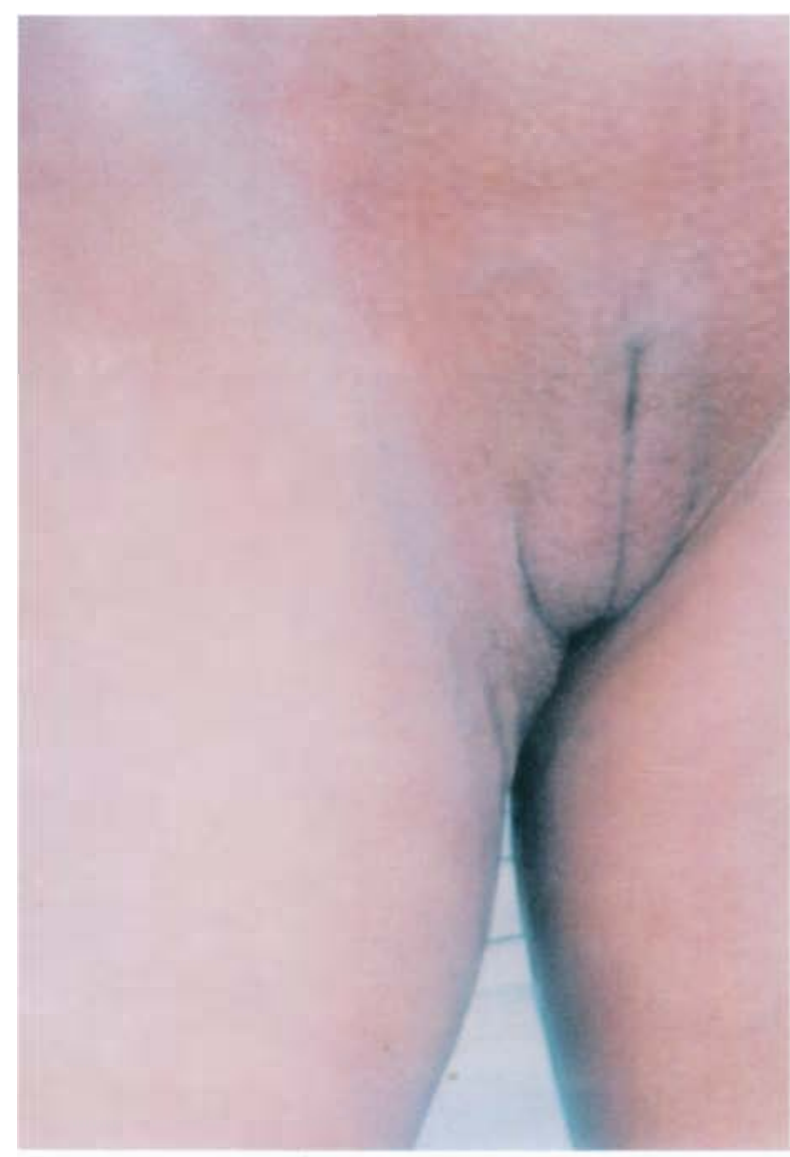

Fig. 2. Vulval varicosity appears as a bulge and sagging down of the labia.

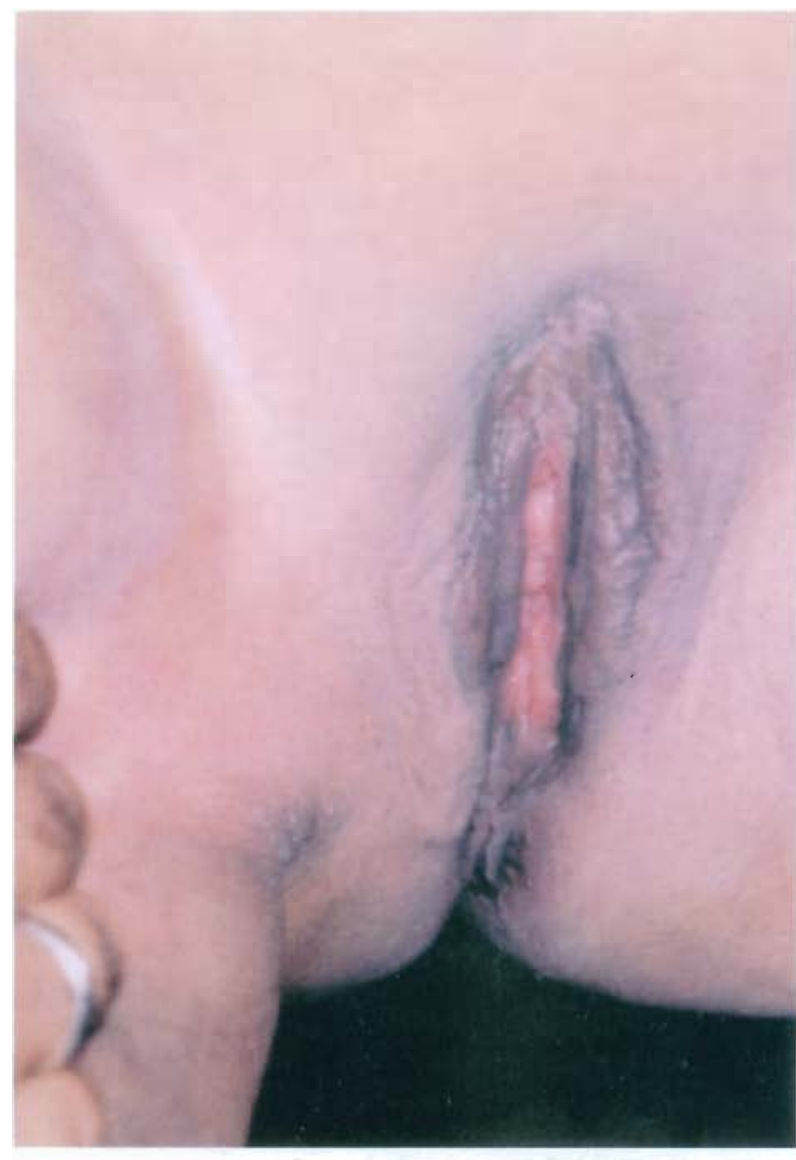

Fig. 3. Extension of the vulval varices to the vaginal mucosa. 

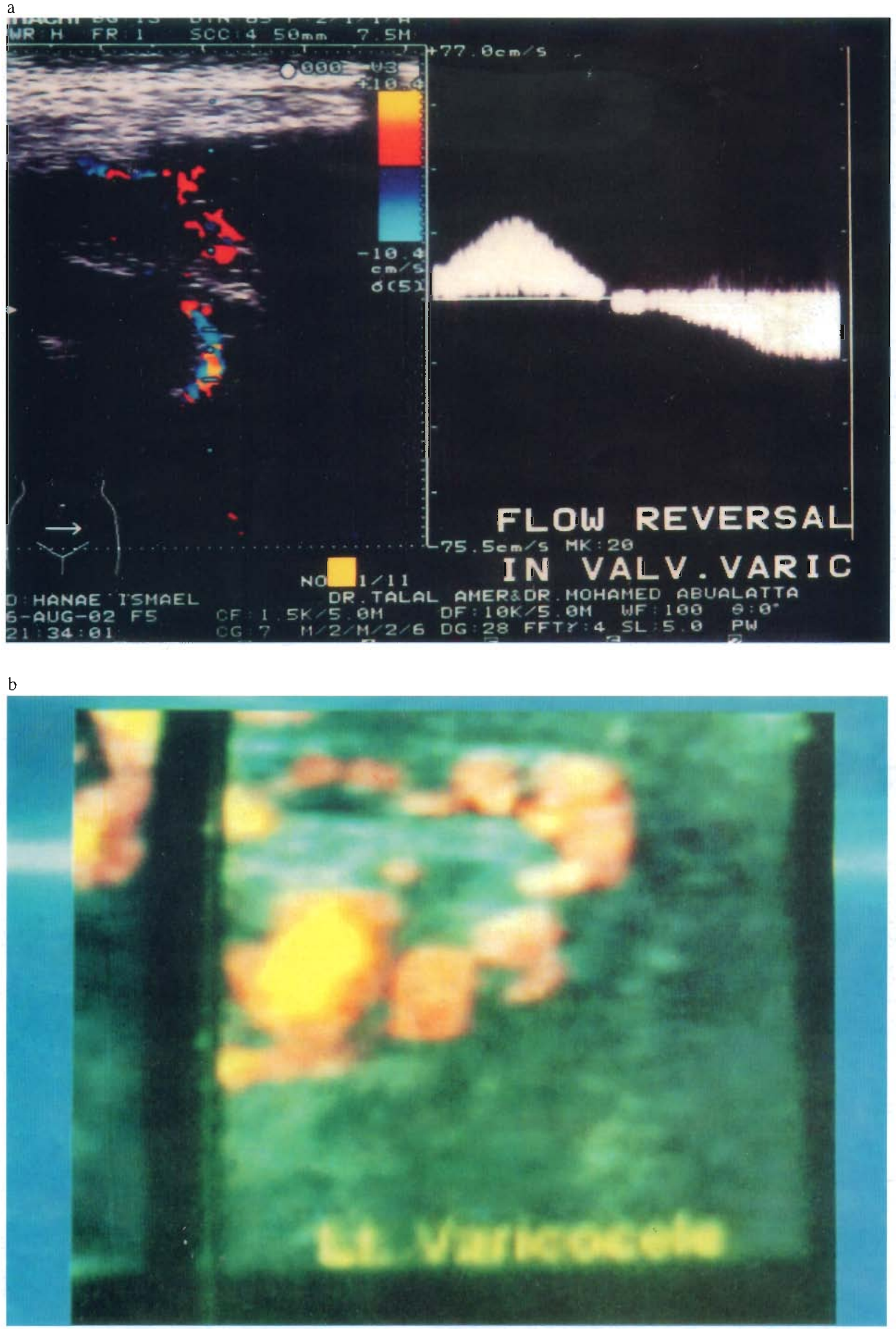

Fig. 4. Retrograde venous flow in the pampiniform plexus (a) and vulval varices (b) by color Doppler. 


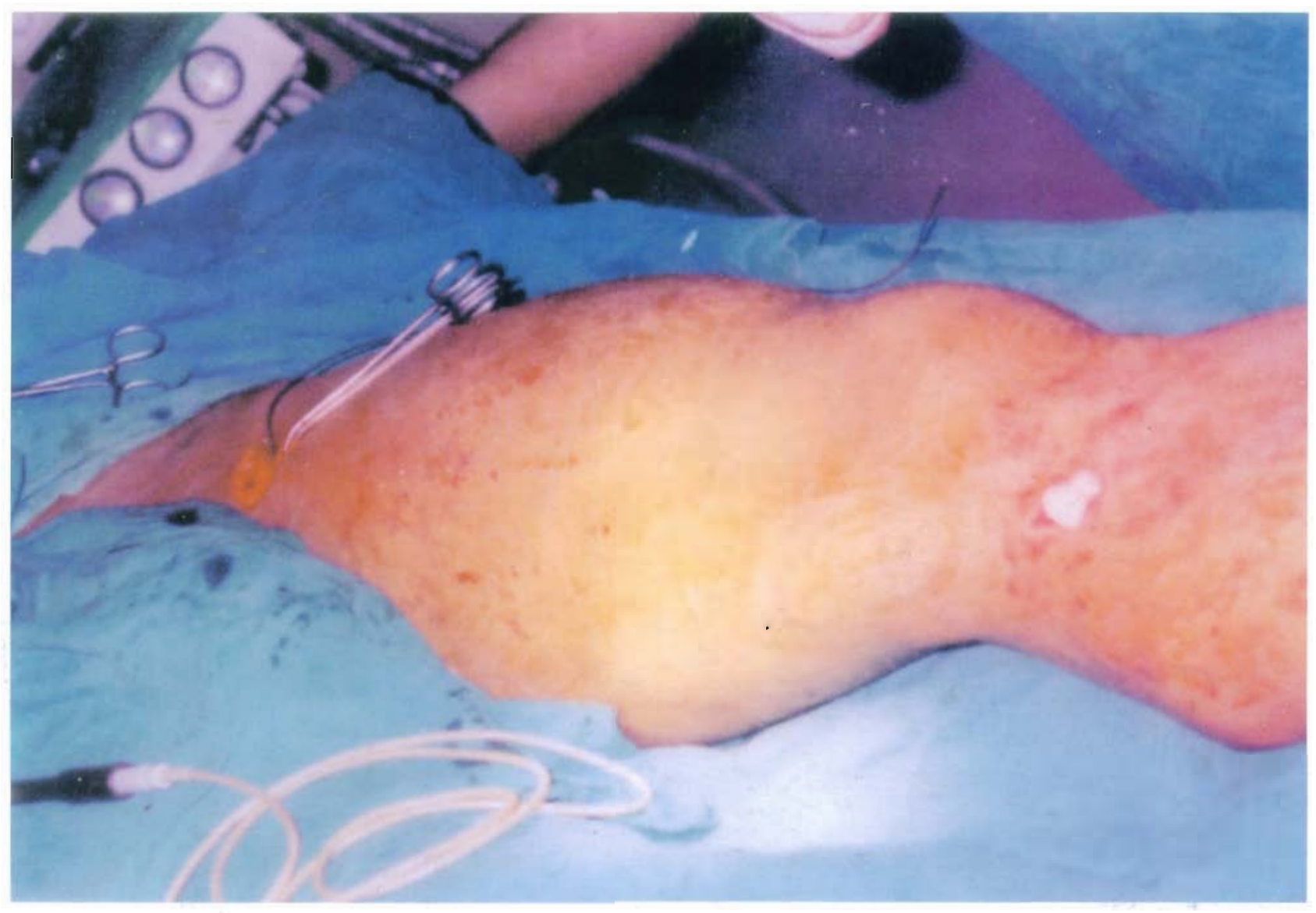

Fig. 5. Advancing the stripper retrogradely in the saphenous vein to the Boyd's point.



Fig. 6. Isolation and division of the pampiniform plexus while the stripper is still unserted in the saphenous vein. 


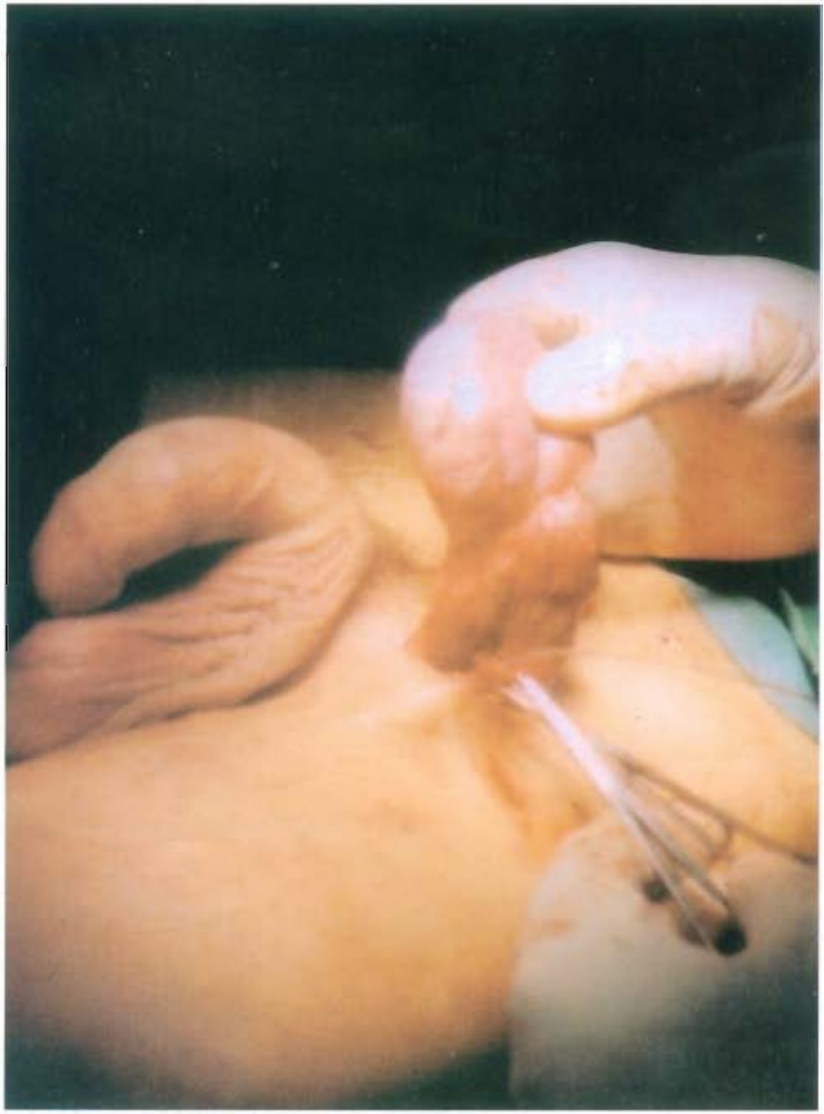

Fig. 7. Delivery of the testis off the incision, the tunica was opened and everted.

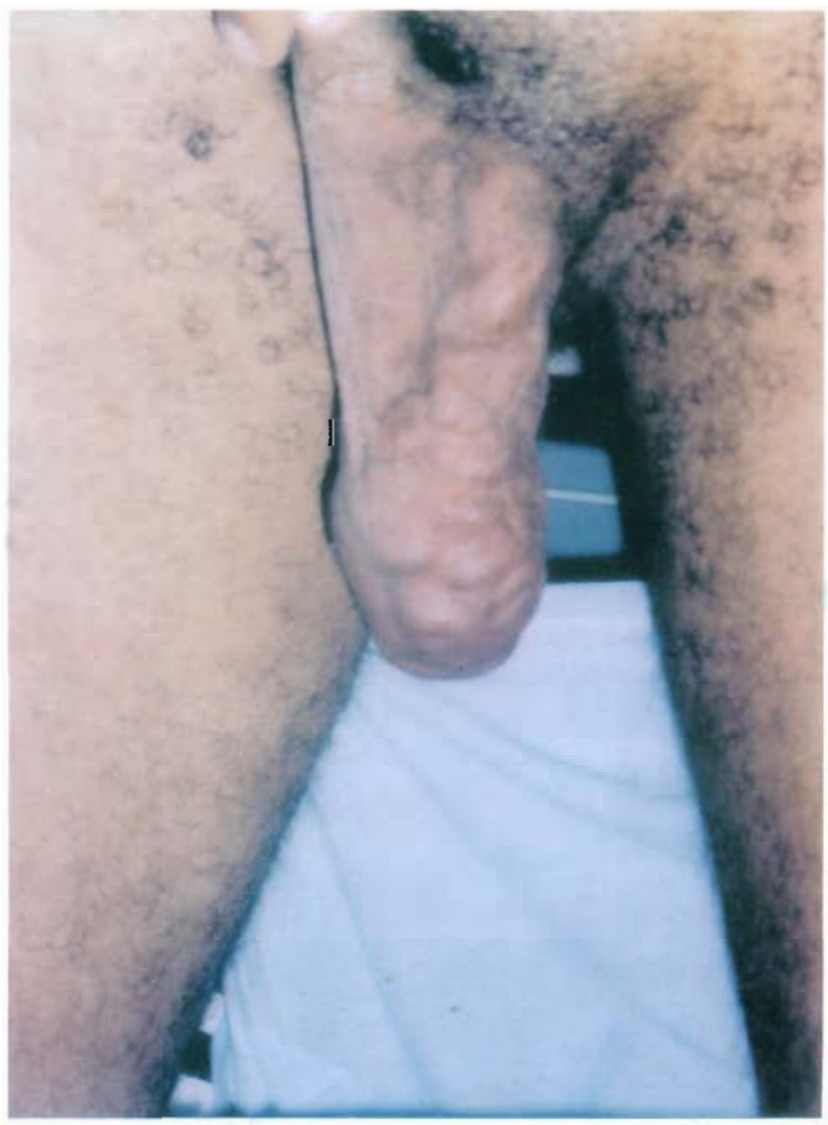

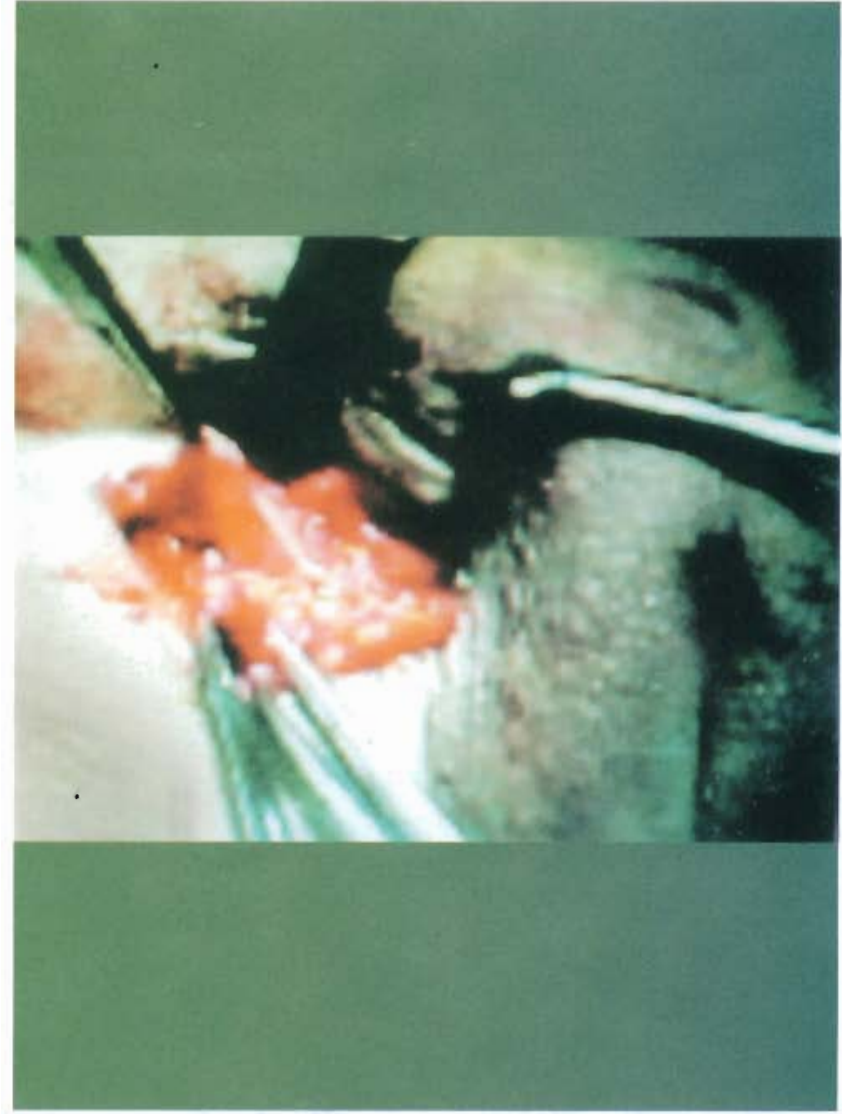

Fig. 8. The vulval varicosity is traced the round ligament and divided through the groin incision.

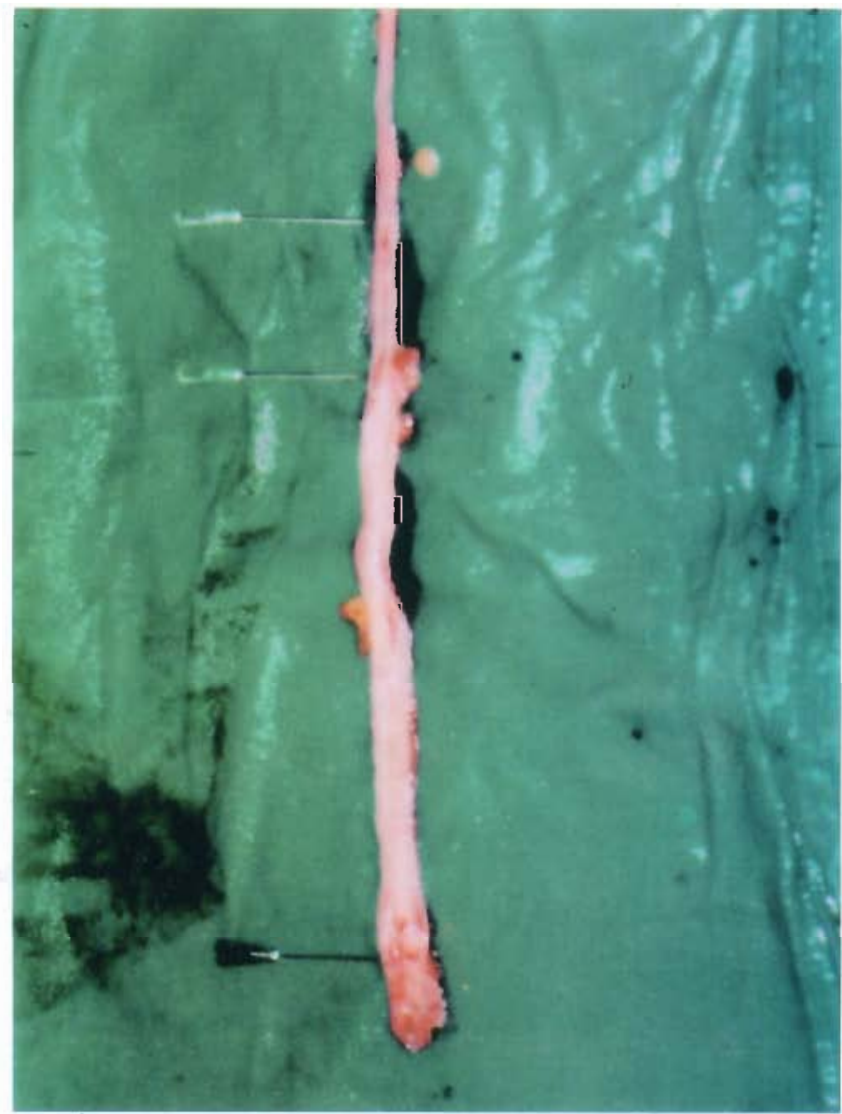

Fig. 9. Three valves were found in the saphenous vein (a) of patient with grade 3 varicocele. 


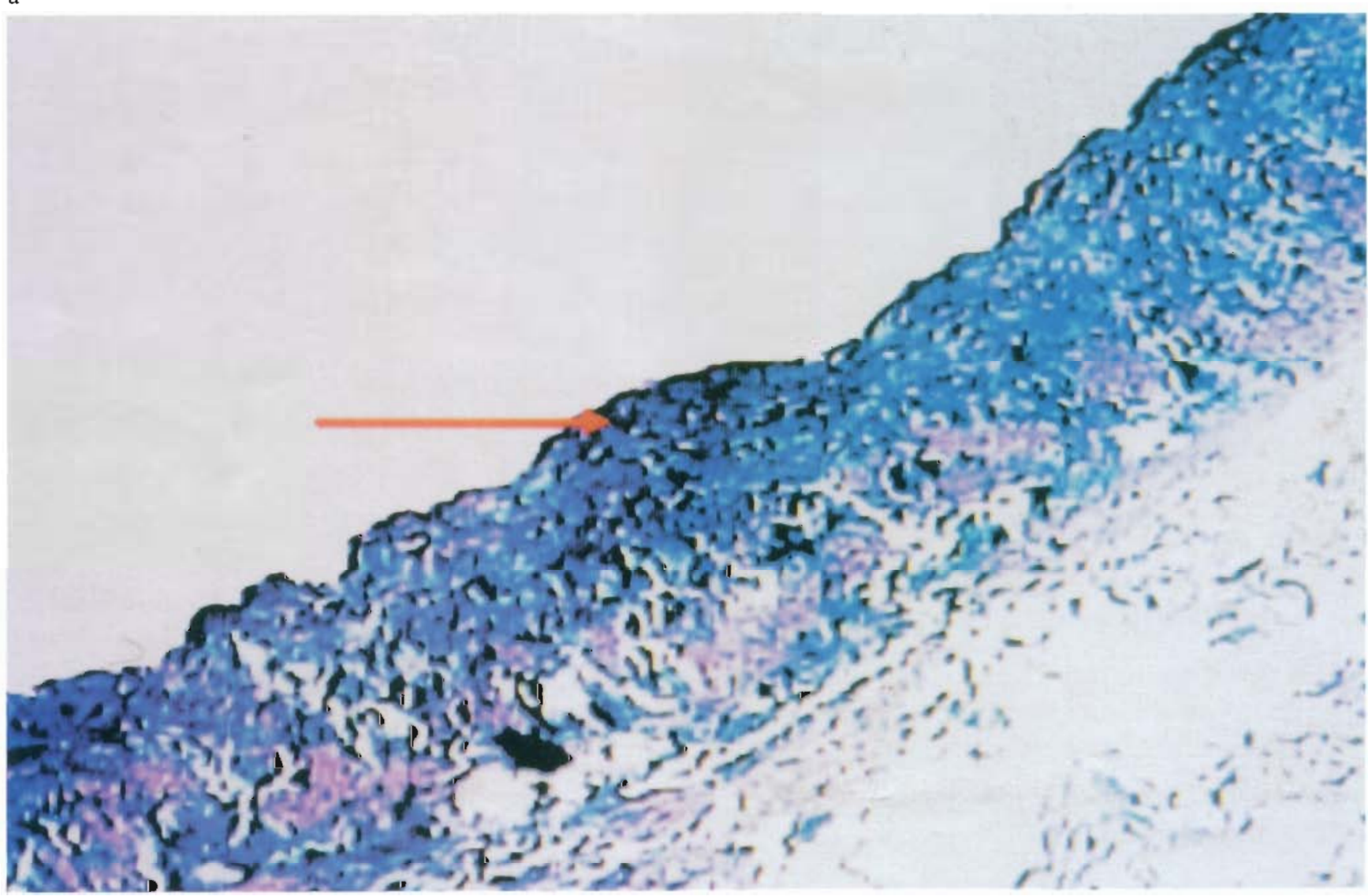

b

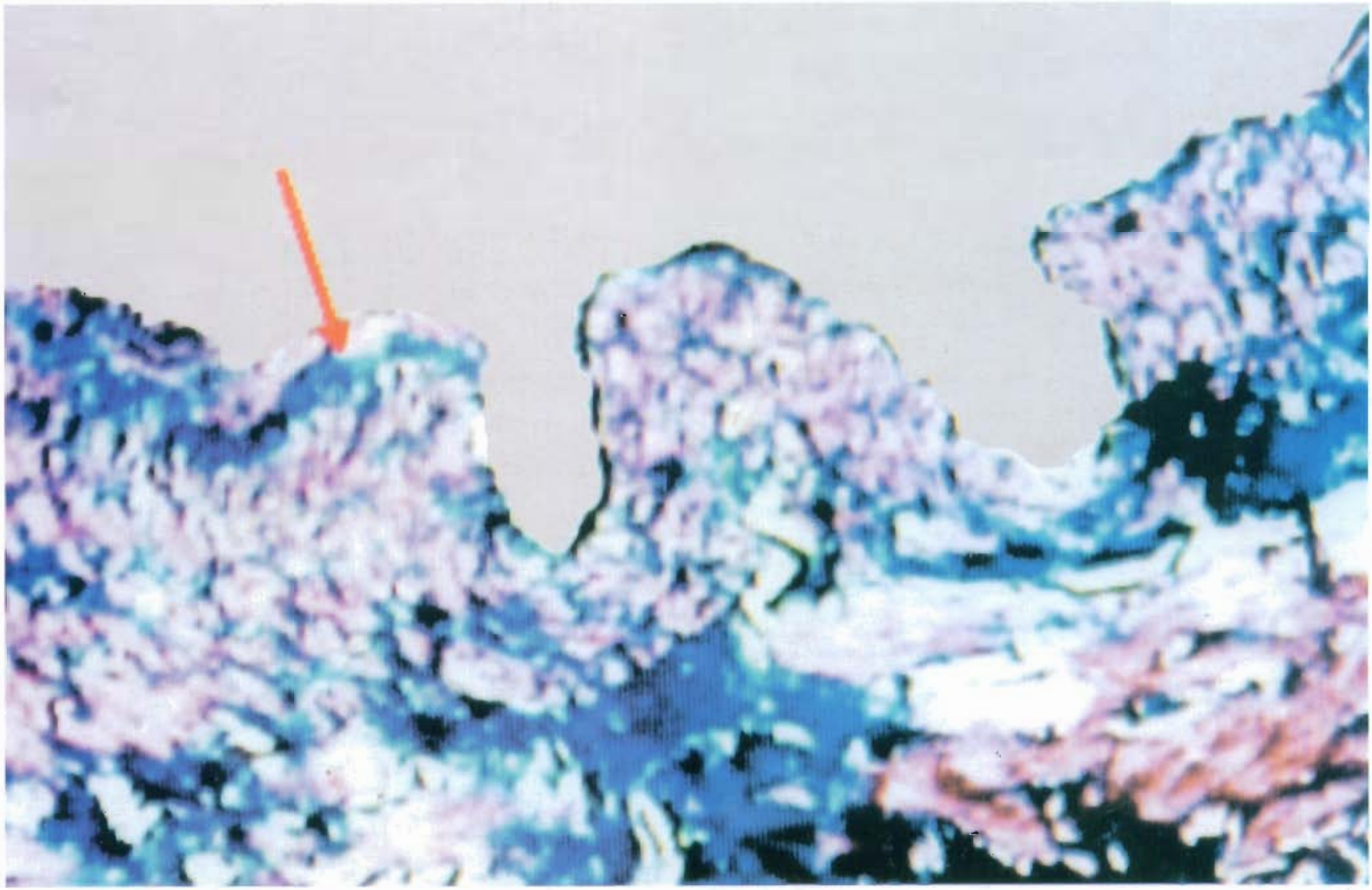

Fig. 10. No difference in the intima, adeventia or valves of either the varicocele or saphenous vein (a), thinning of the media and focal subintimal fibrosis in the varicocele and. saphenous vein coincided with the area of dilatation (b). 


\section{REFERENCES}

1- Oster J. Varicocele in children and adolescents. Scand J. Urol Nephrol 197i ; 5: 27-32.

2- Murray RR, Jr, Mitchell SE, Kadir S, Kaufman SL, Chang R. Comparison of recurrent varicocele anatomy following surgery and percutaneous balloon occlusion J Urol 1986; 135: 286-289.

3- Ciaccio V, Ficola F, Ceccarelli F. Assessment of saphenofemoral junction continence in 42 patients with primary varicocele. Minerva Chir 1995; 50: 469-473.

4- Egar SA, Casper SL. Etiology of varicose veins from an anatomic aspect, based on a dissection of thirty eight adult cadavers JAMA 1943; 123: 148-151.

5- Wyngaarden JB, Smith Jr, LH. Varicose veins. In: Cecil textbook of Medicine Philadelphia; WB Saunders $1985 ; 365$.

6- Nakoda T, Sasagawa I, Kubota Y, Suzuki H, Kakizaki $H$ and, Adachi $Y$. High level of non collagenous protein of spermatic vein in patients with varicocele J Urol 1994; 151: 1539-1542.

7- Santoro G, Romes C, Impellizzeri P, Gentile C, Anastasi G, Santoro A. Ultrastructural and immunohistochemical study of basal lamina of the testis in adolescent varicocele. Fert Steril 2000; 73: 699-705.

8- Weddell JM. A comparison of two methods of treatment of varicose veins. Br J Prov Soc Med, 1970; 24: 65-68.

9- Callum MJ. Epidemiology of văricose veins. $\mathrm{Br} \mathrm{J}$ Surg 1994; 81: 167-173.

10- Smith JJ, Garratt AM, Guest M, Greenhalgh RM, Davies AH. Evaluating and improving health-related quality of life in patients with varicose veins J Vas Surg, 1999; 30: 710-719.

11 - Hargeave T. Varicocele: a clinical enigma. Br J Urol $1993 ; 72: 401-5$.

12- Hamm B. Sonography of the testis and epididymis. Andrologia 1994; 26: 193-96.

13- Trum $\mathrm{JW}$, gubler FM, Laan $\mathrm{R}$ ad vaderenF. The vlue oplption, varicoscreen contact thermography and color Doppler ultrasound in the diagnosis of varicocele. Hum Rep 1996; I1: 1232-1236.

14- gasparini D, Onelio G, Orsolon PG, and Shapiro B. Female "varicocele" Two cases diagnosed by labeled red blood cell angioscintigraphy and treated by percutaneous phlebography and embolization Clin Nucl Med 1998; 23: 420-422.

15- Annoni F, Colpi GM, Marincola FM and Negri L. Doppler examination in varicocele: A standard method of evaluation. J Androl. 1988; 9: 248-252.

16- Liguori G, Trombetta C, Garaffa G. color Doppler ultrasound investigation of varicocele. W. J. Urol $2004 ; 22(5)$ 378-381.

17- McIrvine AJ, Corbett CRRP, aston NO, Sherrif EA, Weiseman PA, Jamieson $\mathrm{CW}$ et al, The demonstration of saphenofemoral incompetence: Doppler ultrasound compared with standard clinical tests. Br J S 1984; 71 : 509-510.

18- Darke SG, Vetrivel S, Foy DMA, Smith S, and Baker S. A. comparison of duplex scanning and continuous wave Doppler in the assessment of primary and uncomplicated varicose veins. Eur J Vas Endovasc Surg. 1997; 14: 457-46I.

19- vasdekis SN, Clarke HG, Nicolaides AN. Quantification of venous reflux using duplex scanning. In Davy A, Stemmer R (ed) Proceeding of Xth world meetin of the Union International de Phlebologie, London 1989 pp 344-349.

20- Karadeniz-Belgili MY, Basar H, Simsir I, Unal B, Batislam E. Assessment of Saphenofemoral Junction continence in patients with primary adolescent varicocele. Pediat Radiol 2003, 33 (9): 603-606.

21- Cleave TL. Aetiology of varicosity. Br Med J, 1972; 15(3): 177.

22- Redmon JB, Carey P, and Pryor IL. Varicocele: the most common cause of male factor infertility. Hum Rep Update 2002; 8: 53-58.

23- Flye MW. venous disorders. In: Textbook of Surgery. Sabiston DC (ed) Philadelphia: WB Saunders 1991: 1490-1501.

24- Weinerth JL, Robertson CN. The male genital system. In: Sabiston DC (ed) Sabiston textbook of Surgery, 15th edition W. B Saunders, Philadelphia London Toronto, pp 1553-1572. 
25- Ahlberg NE, Bartley O, and Chidekel N. Retrograde contrast filling of the left gonadal vein: a roentgenological and anatomical study. Acta Radiol (Diagn) (Stockh). 1965; 3: 385.

26- Hirsh Av. The Doppler assessment of varicoceles and internal spermatic vein rellux in infertile men. Br J Urol 1980; 52: 50.

27- Tibbs DJ, and Fletcher EW. Direction of flow in superficial veins as a guide to venous function in the lower limb. Surg 1983; 93: 758.

28- Dennison AR, Tibbs DJ. Varicocele and varicose veins compared. A basis for logical surgery. Urol 1986; $28: 211-217$.

29- Hollinsheda WH. Anatomy fo surgeons II, 2nd Edn 1971: 856 .

30- Sarin $\mathrm{S}$, Scurr $\mathrm{JH}$, Coleridge-Smith PD. Stripping of the long saphenous vein in the treatment of primary varicose veins Br J Surg 1994; 81: 1455-1458.

31- Stuart WP, Adam DJ, Allan PL, et al. Saphenous surgery does not correct perforator incompetence in the presence of deep venous reflux $J$ Vasc Surg $1998 ; 28: 834-838$.

32- Gloviczki P, Bergan JJ, Rhodes JM, et al. Midterm results of endoscopic perforator vein interruption for chronic venous insufficiency: lessons learnt from the North American Subfascial Endoscopic Perforator Surgery Registrar. J Vasc Surg, 1999; 29: 489-502.

33- Devroey $P$, vandervorst $M$, Naggy $P$, Van Steiteghem A. Do we treat the male or his gamete" Hum Rep 1998; 13: 175-185.

34- Hargreave TB: Debate on the prose and cons of vricocele treatment: in favor of varicoccle treatment. Hum Rep 1995; 10: 151-157.

35- gornud F, Bclin X, Amar E, Delafontaine D, Helenon O, Morcau J ct al. Varicocele: Stratcgics in diagnosis and treatment. Eur Radiol. 1999; 9: 536-545.

36- Comhaire F, zalata A, Schoonjans F; Varicocele: indication for treatment. Int J Androl 1995; 18: $67-71$.

37- Nagler H, Luntz R, Martinis F: Varicocele. In: Lipshultz LI, Howards SS (eds) Infertility in the male, 3rd ed St Louis, Mosby, pp. 336-359, 1997.

38- Marks JL, MNcMahon R, Lipshuly. LI. Predictive parameters of successful varicocele repair. HJ Urol. $1986 ; 136: 609-612$.

39- Lipshultz LI, Corriere JN. Progressive testicular atrophy in the varicocele patients J Urol 1977; 117: 175-176. 